\title{
Public Archaeology's Mammoth in the Room: Engaging Wikipedia as a Tool for Teaching and Outreach
}

\author{
Katherine M. Grillo ${ }^{\circ}$ and Daniel A. Contreras ${ }^{\circ}$
}

\section{ABSTRACT}

Although archaeology has become increasingly concerned with engaging diverse publics, and has embraced the internet as a means of facilitating such engagement, attitudes towards Wikipedia have-understandably-been more ambivalent. Nevertheless, we argue here, Wikipedia's popularity and reach mean that archaeologists should actively engage with the website by adding and improving archaeological content. One way to do this is in the classroom: this paper provides a detailed how-to for instructors interested in having students create new Wikipedia content. We provide a case study in Wikipedia engagement from an advanced undergraduate course on African Archaeology, assess a program (Wiki Education) designed to help, and suggest further avenues for future outreach. We conclude that Wikipedia's utopian mission aligns with many of the goals of public archaeology, and argue that archaeology has much to gain by engaging with-rather than ignoring or even shunning-Wikipedia.

Keywords: public archaeology, Wikipedia, pedagogy

Aunque la arqueología se preocupe cada vez más por comprometerse con públicos diversos, y aunque se haya acogido a la red como medio que pueda facilitar tal compromiso, la disciplina sigue - por razones comprensibles - ambivalente hacia el rol de Wikipedia. Sin embargo, aquí planteamos que por la popularidad y amplia influencia de Wikipedia los arqueólogos deben comprometerse a contribuir y mejorar el contenido de este recurso en internet. Un sitio donde se puede realizar tal compromiso es el aula: aquí se proveen instrucciones detalladas por los instructores que se interesan en involucrar a sus estudiantes en la creación y/o mejora de contenido para Wikipedia. Discutimos un caso práctico de este tipo de trabajo con Wikipedia desarrollado en un curso bachiller avanzado en arqueología africana. Por este medio, evaluamos un programa (Wiki Education) diseñado para apoyar tales esfuerzos, y sugerimos otras posibilidades para este compromiso. Concluimos que el objectivo utópico de Wikipedia se alinea con varios objectivos de la arqueología pública y planteamos que la arqueología puede ganar mucho comprometiendose con - en lugar de ignorar o incluso rechazar - Wikipedia.

Palabras clave: arqueología pública, Wikipedia, pedagogía arqueológica

An oft-expressed concern within and about the discipline of archaeology in recent decades is public engagement, cited as both practical necessity and ethical imperative. It is a practical necessity in that without public engagement, awareness and funding of archaeological research and conservation of archaeological sites are unlikely to find continued popular support. It is an ethical imperative in that archaeologists serve as stewards of the public's cultural heritage. Archaeological research is often publicly funded, and archaeologists are not the only stakeholders with interests in the past.

Beginning in the late 1990s, the internet has often been touted as a potential means for public engagement: it can allow wide dissemination of information and give archaeologists access to publics with whom they might not otherwise communicate (see McDavid 2004). A widespread result has been the increased use of social networks by academics and archaeological professionals
(Perry and Beale 2015; Richardson 2012), as well as the development of ever-more-sophisticated archaeological websites, increasingly media-rich, interactive, and even multi-lingual. Even while such websites have proliferated and hit counts have climbed, however, archaeologists have largely ignored - if not actively scorned - an obvious interface: Wikipedia.

The publics whom archaeologists seek to reach now overwhelmingly rely on Wikipedia as a source of basic information (see Schroeder 2018:122-124). However, there is remarkably little discussion in the public archaeology literature about the central role that Wikipedia plays in the global dissemination of archaeological knowledge. This is not to suggest that archaeologists should passively accept Wikipedia's prominence, nor necessarily embrace its leading role - but it is foolish, we would argue, to ignore Wikipedia. The need for accurate and widely available information about archaeology is acute, especially considering our discipline's

Advances in Archaeological Practice 7(4), 2019, pp. 435-442

Copyright 2019 을 Society for American Archaeology. This is an Open Access article, distributed under the terms of the Creative Commons Attribution licence (http://creativecommons.org/licenses/by/4.0/), which permits unrestricted reuse, distribution, and reproduction in any medium, provided the original work is properly cited.

DOI:10.1017/aap.2019.8 
notable problems with the proliferation of pseudoscientific theories in the public realm (Ancient Aliens, Legends of the Lost, and similar television programs are obvious and egregious offenders). Whereas archaeologists might understandably shun a journal given to publishing pseudoscientific theories for fear of lending it credibility, the uniquely open nature of Wikipedia allows/demands a different sort of engagement, wherein archaeologists actively work with Wikipedia to ensure the completeness and accuracy of its entries. Moreover, Wikipedia's place in the public consciousness suggests that it could serve as an important medium through which archaeologists might convey vital messages not just about archaeological sites, eras, or scholars, but also about archaeological debates and ethics.

Here, we tackle a small part of what should ultimately be a much broader conversation about the cases for and against professional archaeologists' engagement with Wikipedia. We describe the Wiki Education program, an initiative designed to aid professors and other educators with classroom-based content creation, and we argue that it offers a means of engaging with Wikipedia that has both outreach potential and pedagogical value. Our discussion emphasizes the ease and importance of Wikipedia-based classroom activities and serves as a basic how-to for instructors interested in implementing such programs.

\section{ARCHAEOLOGICAL ENGAGEMENT WITH WIKIPEDIA}

Wikipedia reaches an astoundingly wide audience. The site attracts roughly 374 million unique visitors monthly (see http://en. wikipedia.org/wiki/Wikipedia:About), and a recent study determined that Wikipedia receives traffic from almost one-third of all mobile phone users per month, more than websites for Fox News, CNN, and the New York Times combined (Knight Foundation 2016). Search terms entered into Google routinely list Wikipedia pages as the first hit, ensuring that the user's first exposure to particular archaeological sites, themes, or scholars is often a Wikipedia page. Such exposure is generally much higher in volume than any academic publication or project website: the Wikipedia page for Machu Picchu, for instance, averages well over 6,000 pageviews per day. ${ }^{1}$

A large community of editors from around the world contributes to archaeology pages on Wikipedia, and an extensive project (WikiProject Archaeology) is dedicated to improving the site's archaeological content. Many well-known sites, scholars, and other archaeological topics have extensive and well-referenced Wikipedia pages already. There are, however, significant gaps in coverage and quality for many parts of the world and for many archaeological eras. In Africa, for example, there were several UNESCO World Heritage Sites without Wikipedia pages at all when the first author began editing in 2014. Across the board, academic literature is often under-referenced in favor of undervetted material more readily available in the popular media, and it may be difficult for some editors to distinguish between fringe theories and up-to-date, widely accepted archaeological research. Critics have also worried that wiki-style efforts can be a form of intellectual mob rule, effacing nondominant narratives (e.g., Harrison 2010).
The open-editing nature of Wikipedia is such that archaeologists can, in addition to offering critiques, directly improve the site: any archaeologist willing to volunteer has the ability to add accurate information and direct readers to relevant, high-quality publications. Amara Thornton (2012) has pointed out that even simply adding links on Wikipedia pages from pop culture pages (e.g., "Indiana Jones") to detailed pages about archaeological figures, sites, or methods can be a way to productively channel the public's interests. At least some in archaeology's sibling disciplines in the social sciences and humanities have issued similar calls to embrace Wikipedia for both ethical and practical reasons (e.g., sociology [Olin Wright 2011], public policy [Infeld and Adams 2013], and history [Rosenzweig 2006 and Chandler and Gregory 2010]).

We recognize that such public service is often poorly rewarded in academic and professional systems, although at some institutions this may be changing. Still, any investment of time in Wikipedia editing likely comes at the expense of time engaged in activities such as publication, grant-writing, and course preparation that are more likely to be better rewarded by those making hiring, tenure, and promotion decisions. Wikipedia's potential as a pedagogical tool offers an exit from this dilemma: involving students in Wikipedia page creation and editing serves not simply as an efficient means of archaeological outreach, but can also invest and immerse students in the production of archaeological content.

Students at all levels are often taught to treat Wikipedia with skepticism. Even so, university students report using Wikipedia far more often than they do library databases: one-third of students in one surveyed group in fact use Wikipedia for academic research (see Lim 2009). We see no problem with this if Wikipedia pages point students to appropriate literature in academic journals, books, and other peer-reviewed sources - which academic engagement with Wikipedia can ensure. Better still, by actively editing Wikipedia pages themselves, students improve their abilities to critically evaluate problematic Wikipedia pages, and they gain experience in reviewing academic literature. Student motivation and dedication to producing quality writing is overall high, given the understanding that thousands of people will be reading their work.

This process is facilitated by the Wiki Education initiative, whose mission is to assist instructors in implementing classroom editing activities. Below, we outline a classroom implementation of Wikipedia editing and then evaluate its success in African Archaeology courses offered at a regional comprehensive university.

\section{HOW-TO: STUDENT EDITING WITH WIKI EDUCATION}

The Wikipedia Education Program was established in 2010 by the Wikimedia Foundation as a means of supporting university instructors interested in using Wikipedia in their classrooms. Branches of the now-global Wikipedia Education Program now exist in approximately 100 countries (Helaine Blumenthal, personal communication 2019; see also Davis 2018). In 2013, branches in the United States and Canada spun off and together formed the independent 501(c)3 nonprofit Wiki Education. The Wiki 


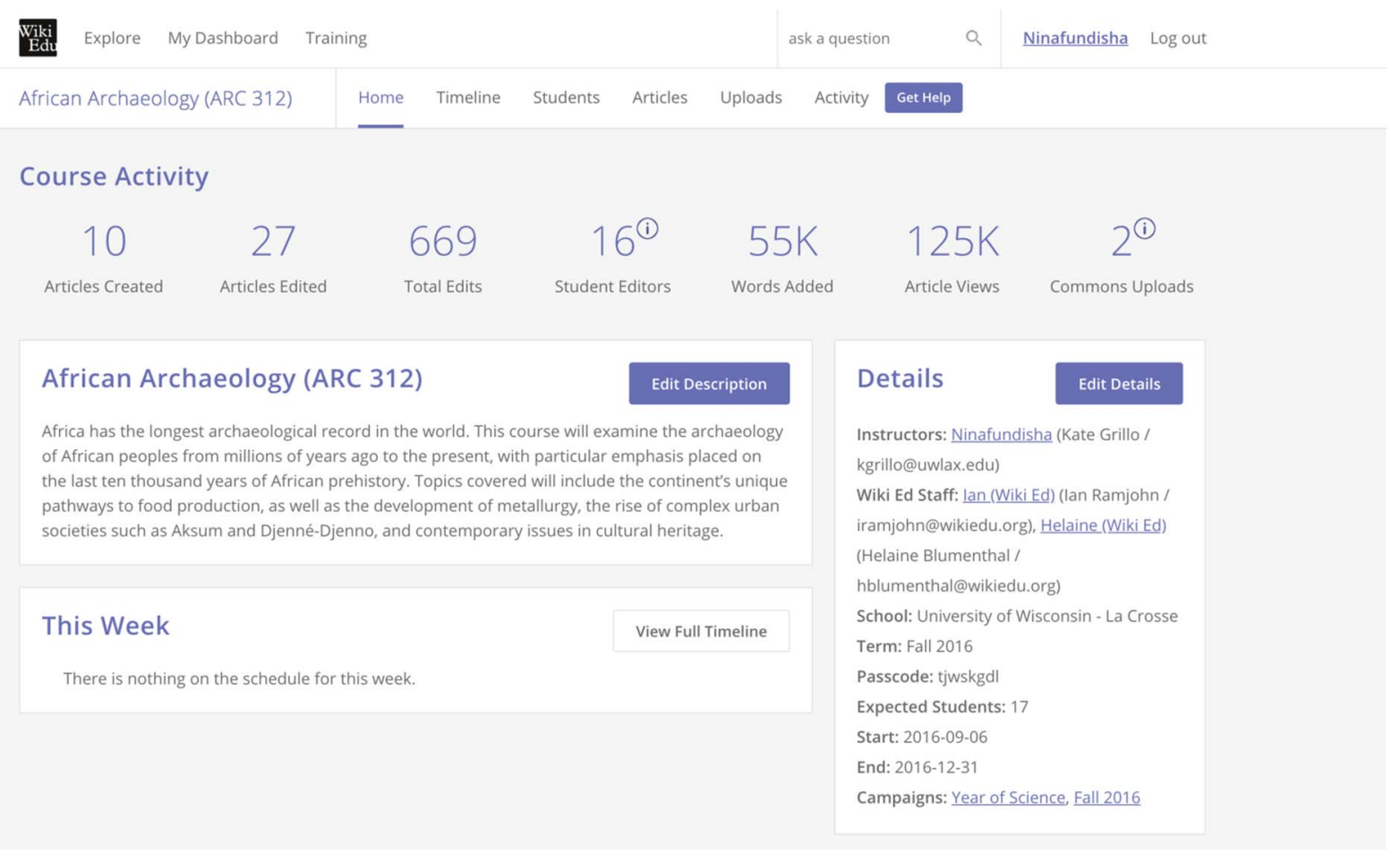

FIGURE 1. Screenshot of the course dashboard for ARC312, African Archaeology, taught in the fall semester of 2016 at the University of Wisconsin-La Crosse.

Education program provides full-time support in instructor and student training, course logistics, and outreach. Wiki Education also provides a very helpful course homepage, the "dashboard," to all instructors (Figure 1). Anyone interested in teaching with Wikipedia or in contributing to Wikipedia as an expert is welcome to contact Wiki Education directly. ${ }^{2}$ Instructors can certainly have students edit Wikipedia without assistance from Wiki Education, but the resources provided by Wiki Education are, in the experience of the first author, extremely useful. The following steps are recommended:

1. Instructors register for a free account and choose a user name. Users can also create personalized user homepages and an associated "talk page" on which editors can communicate with each other.

2. The Wiki Education dashboard can then be used to create a course timeline, organized week by week, that tracks all required assignments. Students register and choose user names as well, which appear on the course dashboard along with statistics about content that they contribute to Wikipedia (e.g., total numbers of edits, numbers of characters added, and page views).

3. Both instructors and students complete online tutorials covering topics including Wikipedia policies, basic editing skills, how to add images and other media, and proper referencing practices. Student completion of training modules can be tracked on the dashboard. Additional resources, including educational brochures and classroom handouts, are available here. Note that instructors do not need previous experience editing Wikipedia before joining the Wiki Education program. In our experience, the learning curve for editing is very manageable. There is a fully functional visual editor for Wikipedia that allows users to easily add or delete text, add photos or maps, and adjust page layouts through an interface as simple as basic word processing software. Simple Wikimarkup code can be employed to do more advanced editing and formatting.

4. Students select articles to either create or improve, and then participate in both collaborative and individual editing. Selecting articles to work on can itself be an extended process, as students must conduct enough initial background research on their proposed topics to determine whether a topic is a) notable to enough to have a page, or $b$ ) has a page that is underdeveloped enough to warrant expansion. If students choose to create a page about a living scholar, instructors may wish to have their student contact that scholar for permission to proceed.

5. Once a topic has been selected, students can begin editing in a personal "sandbox" that Wikipedia makes available for every user. Sandboxes allow users to practice editing, learn the referencing system, and experiment with formatting before any information is added to Wikipedia's "mainspace" (i.e., the encyclopedia proper). The sandbox also makes it easy for instructors to review their students' work before signing off on publication. When ready, students can begin adding their new content or revisions to the mainspace. Other editors may begin to interact with their work; if an article is underreferenced, for example, it may get tagged as needing additional citations. Peer-review exercises conducted in class can facilitate the exchange of helpful advice about finding sources and can ease anxiety about the more technical aspects of Wikipedia editing. A dedicated staff member at Wiki Education 
is available to answer questions and assist with any problems or other issues that might arise.

6. Finally, instructors can encourage students to meet additional editing targets, a practice that can be helpful in terms of student motivation. Students, for example, can create a new article or expand an existing article to be eligible for the "Did You Know..." section of the Wikipedia homepage. Particularly well-researched and well-written articles can also be nominated for "Good Article" status. Nominated articles go through a lengthy review process by experienced editors, and if successful the article receives a "Good Article" badge on its main page.

\section{A Note about "Edit Wars"}

Instructors may perceive several risks when having students edit Wikipedia content. Contributors, for example, may get sucked into "editing wars": conflicts with other Wikipedia editors over content. Controversial topics, or topics in which the general public is already deeply invested, may be more difficult for editors to approach. Through the Wiki Education dashboard system, short notes are automatically placed on pages being actively edited by students, alerting the community that a student's work is in progress. Other editors tend to be more forgiving and helpful as a result. Students' efforts may be edited or deleted, but it is considered poor practice to remove well-referenced, well-researched contributions, and deletions or unconstructive editing can be reversed. Again, all pages on Wikipedia are patrolled by a broader community of Wikipedia editors who (even if not archaeologists themselves) help to uphold community etiquette standards and ensure conformity to strict writing, referencing, and editing guidelines (see the "Five Pillars" of Wikipedia and a list of policies and procedures).

\section{Student Assessment and Arenas for Further Engagement}

It is worth noting for potential instructors that Wikipedia articles are a different beast than most term papers. The goal in creating and editing Wikipedia pages is not to present new ideas or analyses but rather to identify important subjects, evaluate and synthesize the existing literature on those subjects, and present clear summaries for a general audience. Students found this exercise in archaeological synthesis more challenging than perhaps anticipated, but it did seem that practicing this critical skill improved their ability to conduct (and report) original research in later courses. Anecdotally, "background" sections in papers written by past student participants in the Wikipedia project were often dramatically improved, raising the quality of their research overall. The Wiki Ed Foundation recently published a mixed-methods study assessing student learning outcomes for participants in the Wikipedia Education Program, and found that classroom assignments designed to critique existing Wikipedia articles were perceived by students as very effective in helping them develop skills in peer reviewing, writing literature reviews, and writing for the general public (McDowell 2017:8). Everyone from high school students to graduate students may benefit in similar ways from participation in the Wiki Education program. For graduate students in particular, learning how to communicate research to non-specialist audiences is an important (and marketable) skill.

\section{CASE STUDY IN THE CLASSROOM: AFRICAN ARCHAEOLOGY}

In practice, taking advantage of Wiki Education has proven effective both as pedagogy and as public outreach. During the fall semesters of 2014 and 2016, one of us (Grillo) offered an upper level undergraduate African Archaeology course at the University of Wisconsin-La Crosse (UWL). Each student in ARC 312: African Archaeology was required to create or substantially expand one Wikipedia article as their final class project (see Figure 2 as an example). This exercise was driven by two goals: 1) the desire to invest the traditional reportage of a term paper in an area-based survey course with some added interest and gravitas, and 2) the observation that existing content on Wikipedia related to African archaeology (outside Egypt) is still, by our estimation, far more limited than for many other better-known archaeological regions.

The resulting assignment was analogous to a more traditional one: by the end of the semester, students were expected to have contributed an amount of work equivalent to writing a term paper towards creating and/or improving a Wikipedia page. While this made some additional demands of the students-namely having to become familiar with the Wikipedia editing process-it also resulted in an important pedagogical dividend: students found themselves producing something that was not "just" for class. As a result, they became more invested and were both empowered and sobered by the fact that they were making a real contribution to a resource that-they knew from experiencemight be widely used.

In their course evaluations, the first cohort of ARC 312 students often commented that editing as a class before being left to edit on their own would have alleviated anxiety about future assignments. In the second iteration of the course, the disastrous Wikipedia article on "African archaeology" was thus targeted for collective editing. Students found this orientation helpful and liberating: selection of a demonstrably poor Wikipedia article emphasized to students that they not only could easily master the technical skills necessary, but also had, or could certainly develop, sufficient expertise to contribute meaningful edits. The Wiki Education program facilitated this work by providing a structured set of guidelines, tutorials, and other resources on Wikipedia editing for both instructor and students.

Students in ARC 312 created new articles for UNESCO World Heritage Sites that did not have existing pages already (Songo Mnara, Tiya, and others) and either created or greatly expanded content for other sites including Chibuene, Manyikeni, Kariandusi, Mumba Cave, and Gobero. Students also grappled with various archaeological concepts and debates, adding and/or improving pages for the Kintampo Complex and the Middle Stone Age, and they researched specific information about looting and the antiquities trade for Djenné-djenno and the Nok culture. Students at UWL also created biographical pages for a number of prominent women in African archaeology, including Diane GiffordGonzalez, Fiona Marshall, and Alison S. Brooks.

Since the Fall 2016 semester started, the articles created and/or substantially edited by UWL students during that semester's ARC 312 course have been viewed over 125,000 times. Students also 


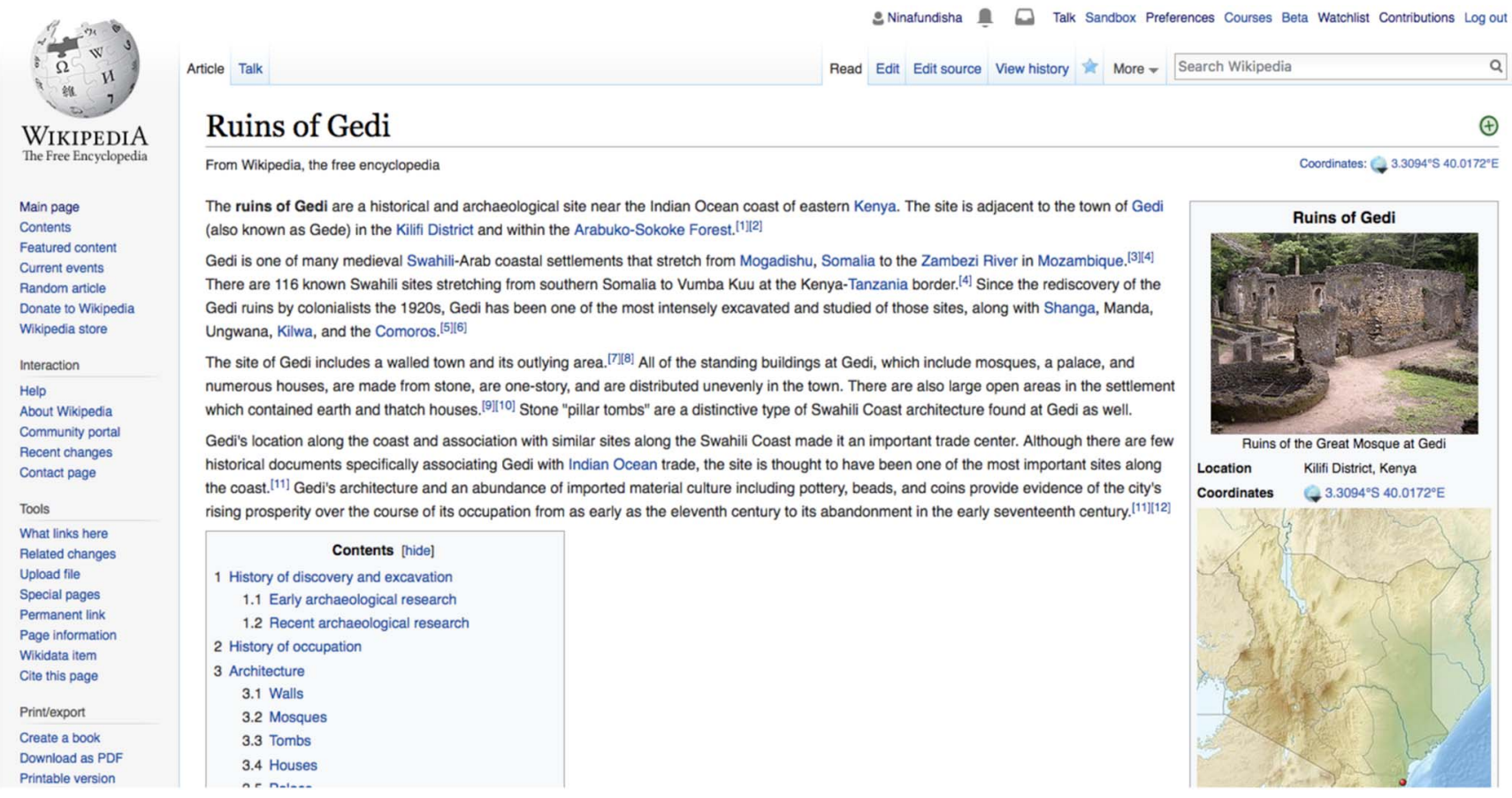

FIGURE 2. A sample Wikipedia page with content created by a UWL student as part of the Wiki Education program.

met additional editing targets, including being featured on the "Did You Know..." section of the Wikipedia homepage. Figure 3 shows a screenshot of this homepage on a day when an article on Mumba Cave, substantially edited by a UWL student, was selfnominated for and appeared in the "Did You Know..." section. That day, the article received more than 2,000 pageviews (Figure 4). Pages substantially improved by UWL undergraduates were also awarded "Good Article" status. See, for example, the Wikipedia pages for the Middle Stone Age and the ruins of Gedi.

Encouragingly, ARC 312 students, at least when editing African archaeology pages, encountered very little resistance (and to the contrary, most have found the broader editing community very supportive).

\section{BROADER IMPACTS}

Given the growing emphasis on job training in higher education, activities such as participation in the Wiki Education program that both provide marketable skills and promote media literacy, may be particularly valuable. Post-graduation, one student in ARC 312 (a History major) worked as an intern on an organization's Wikipedia pages and posted the following update on the first author's talk page: "So, even though my internship is definitely not in African archaeology, the class really helped me a few years down the line." We would also note that having students engage in Wikipedia page creation and editing is a productive way to address broader issues with the platform, such as Wikipedia's well-documented gender imbalance that exists in terms of both who edits (men still far outnumber women) and the content that results (see Hargittai and Shaw 2015, Lam et al.
2011). The TrowelBlazers project-dedicated to promoting awareness of women's contributions to archaeology, geology, and paleontology—has hosted successful Wikipedia edit-a-thons, organized and scheduled events in which various editors work to improve content based around some common theme. TrowelBlazers has focused on improving coverage of women in archaeology (see Hassett et al. 2018); instructors and students could participate in or even organize such special events.

In his ethnography of Wikipedia, Dariusz Jemielniak (2014) discusses in detail the ways in which the Wikipedia community deals with editing conflicts, gender biases, and other problems - and how the community has nonetheless created a vast repository of knowledge that is both globally accessible and entirely free. The project is utopian, and the ideals of accessibility and open access are ones cherished by academics, even as academic publishing norms and often rarefied academic discourse can work against them. Wikipedia, at its best, offers academic archaeologists a chance to further these ideals that they espouse. As Erik Olin Wright (2011:6) writes about the site's promise:

[Wikipedia] embodies ideals of equality, open access, participation, and deliberation in a domination-free environment. It has created a public good available to all. It encourages a demystification of credentialism as a source of authority. It softens the boundary between producers and consumers of information, making everyone who uses Wikipedia a potential contributor as well. It is part of a broader movement that challenges exclusionary forms of intellectual property and treats knowledge as a vital commons. It celebrates contributions rooted in motivations of 


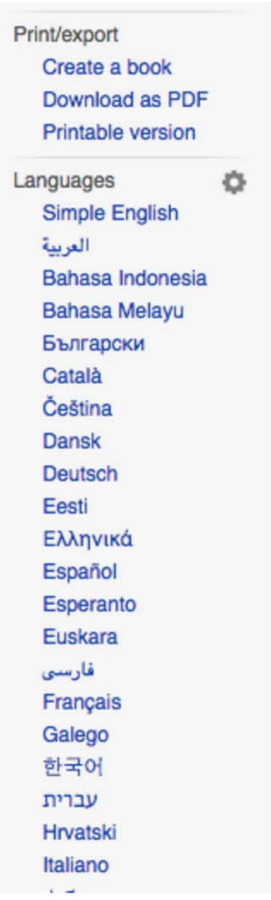

(ruil articie...)

Recently featured: Bob Windle - Carl Hans Lody - Gough Whitlam

Archive - By email - More featured articles...

\section{Did you know...}

From Wikipedia's new and recently improved content:

- ... that other millers viewing the fully-automated flour mill designed by Oliver Evans (pictured) could not appreciate its advantages?

- ... that South Africa has a hotline to report illegal parking in bays designated for disabled drivers?

- ... that Mumba Cave contains a large assemblage of archaeological evidence for the transition between the Middle Stone Age and Late Stone Age in East Africa?

-... that Orange Is the New Black character Lorna Morello has been said to have "the most amazing accent on television"?

-... that Italian artist Trento Longaretti was named after his dead sibling?

-... that Big Girls Don't Cry is a nonfiction book that argues that "the women's liberation movement found thrilling new life" as a result of the 2008 U.S. presidential election?

-... that there are rubber rooms below the launch pads at Kennedy Space Center? Archive - Start a new article - Nominate an article

FIGURE 3. Screenshot of the "Did You Know..." section featuring Mumba Cave.

\section{On this day.}

November 8: St. Church)

- 1576 - The pr the Pacificatic rebelling provi an alliance to , country.

- 1644 - The Si emperor of the collapse of the China.

- 1861 - Americ mailship Trent Europe, spark Kingdom and

- 1965 - Americ New York City because of inf as the John F.

- 1987 - A Prov

\section{Wikipedia article traffic statistics}

\section{Mumba Cave has been viewed 2567 times in the last 30 days.}

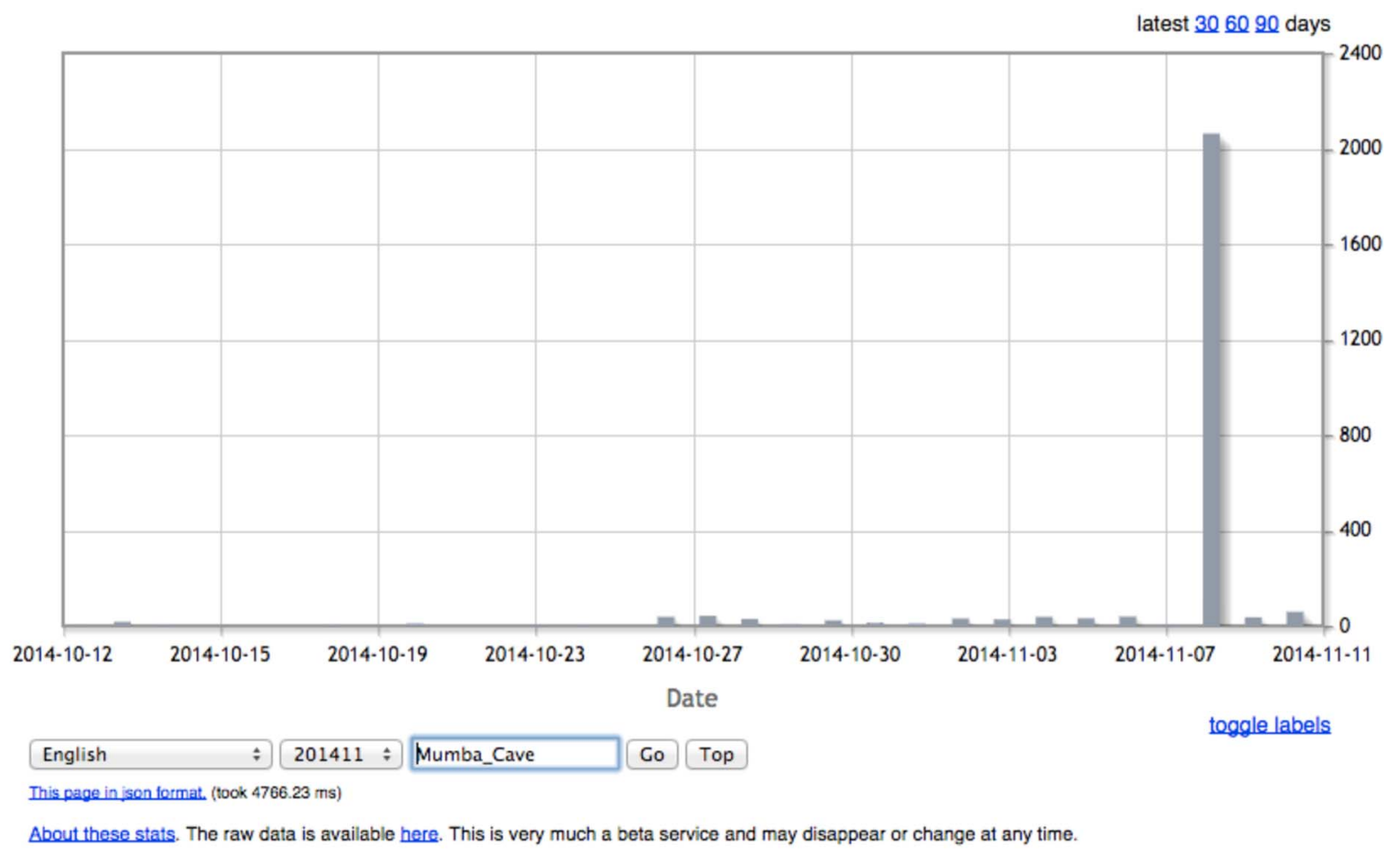

FIGURE 4. Screenshot of Mumba Cave pageview statistics illustrating the spike on "Did You Know..." day. 
intellectual curiosity and the pleasures of collaborating with a far-flung network of interested people.

Archaeologists might_-if cautiously_embrace this promise. However, archaeologists have, we suggest, yet to take full advantage of Wikipedia's potential. Wikipedia is not often utilized as a means of dissemination of archaeological information and outreach to the public, nor as a pedagogical tool. Nor have archaeologists realized Wikipedia's potential for incorporating more, and more diverse, voices in archaeological conversations: frequent calls to respect and encourage multivocality in archaeological interpretation (Atalay 2008; Hodder 2008; McAnany and Rowe 2015; McDavid and Brock 2015) can in fact be put to fairly immediate practice through Wikipedia. As a result, we see potential in not only training American undergraduate students to contribute well-sourced and detailed archaeological content (and to develop the tools to identify sub-par content), but also in encouraging contributions to Wikipedia by diverse communities of scholars and students worldwide. Editing is free and can be done from one's phone, and training is readily available online. There are currently 300 Wikipedia encyclopedias in languages other than English as well; improving the archaeological content on those pages is an opportunity available to all and would help in many ways to counter the hegemony of English in public archaeological discourse.

We also urge our colleagues to use Wikipedia as a means of challenging the rampant propagation of "alternative facts" in their many forms, and to engage in this venue for scientific communication that may reach more people than any other. Many concerns about editing Wikipedia (time investments, potentially low professional rewards, editing conflicts, and so forth) are valid-but one way around them, and one that is pedagogically valuable, is student engagement in the creation of Wikipedia content. In the case study discussed here, students gained a deeper understanding of the African archaeological record, demystified knowledge production, became better critical consumers, and built synthesis and communication skills. The African archaeological record, meanwhile, received a great deal more attention from the general public than it would have otherwise. The impact is lasting, both for the students and for Wikipedia. Students may not continue to edit Wikipedia, but they will be more informed consumers of its content. Wikipedia itself has been improved for all users: there now exist substantial and easily updatable pages for a greater number of African archaeological sites of global importance, and they are available to anyone with an internet connection. We hope others will continue to build on this work.

\section{Acknowledgments}

The first author would like to thank her African Archaeology students at the University of Wisconsin-La Crosse for their participation in Wikipedia-based coursework. The Center for Teaching and Learning at UWL provided a small grant (Course Embedded Undergraduate Research Grant for 2016-2017) to Grillo for aid in developing her Wikipedia-based classroom activities, and publication of this article was funded in part by the University of Florida Open Access Publishing Fund. Permits were not required for this project.

Many thanks to Helaine Blumenthal at Wiki Education for reading a draft of this paper and for her essential and ongoing support as the Wikipedia Student Program Manager. Ian Ramjohn also provided very welcome classroom assistance. David G. Anderson (University of Tennessee-Knoxville) has used Wikipedia extensively in North American prehistory courses, and we thank him for his comments on this paper and for graciously sharing his thoughts and experiences. We also thank two other anonymous reviewers, as well as Trinidad Rico, who kindly edited the Spanish abstract. Finally, we would like to dedicate this paper to Erik Olin Wright (1947-2019), whose characterization of Wikipedia as one of the real utopias that he envisioned remains as inspiring as he and his work were.

\section{Data Availability Statement}

No original data were presented in this article.

\section{REFERENCES}

\section{Atalay, Sonya}

2008 Multivocality and Indigenous Archaeologies. In Evaluating Multiple Narratives, edited by Junko Habu, Clare Fawcett, and John M. Matsunaga, pp. 29-44. Springer, New York.

Chandler, Cullen J., and Alison S. Gregory

2010 Sleeping with the Enemy: Wikipedia in the College Classroom. The History Teacher 43(2):247-257.

Davis, LiAnna L.

2018 Wikipedia and Education: A Natural Collaboration, Supported by Libraries. In Leveraging Wikipedia: Connecting Communities of Knowledge, edited by Merrilee Proffitt, pp. 87-104. ALA Editions, Atlanta, Georgia.

Hargittai, Eszter, and Aaron Shaw

2015 Mind the Skills Gap: The Role of Internet Know-How and Gender in Differentiated Contributions to Wikipedia. Information, Communication \& Society 18(4):424-442.

Harrison, Rodney

2010 Exorcising the 'Plague of Fantasies': Mass Media and Archaeology's Role in the Present; or, Why We Need an Archaeology of 'Now.' World Archaeology 42(3):328-340.

Hassett Brenna, Suzanne Pilaar Birch, Victoria Herridge, and Rebecca Wragg Sykes

2018 TrowelBlazers: Accidentally Crowdsourcing an Archive of Women in Archaeology. In Shared Knowledge, Shared Power, edited by Veysel Apaydin, pp. 129-141. SpringerBriefs in Archaeology, Springer, New York.

Hodder, Ian

2008 Multivocality and Social Archaeology. In Evaluating Multiple Narratives, edited by Junko Habu, Clare Fawcett, and John M. Matsunaga, pp. 196200. Springer, New York.

Infeld, Donna Lind, and William C. Adams

2013 Wikipedia as a Tool for Teaching Policy Analysis and Improving Public Policy Content Online. Journal of Public Affairs Education 19(3):445-459.

Jemielniak, Dariusz

2014 Common Knowledge? An Ethnography of Wikipedia. Stanford University Press, Palo Alto, California.

Knight Foundation

2016 Mobile America: How Different Audiences Tap Mobile News, Part 2. Electronic document, https://medium.com/mobile-first-news-how-peopleuse-smartphones-to/mobile-america-how-different-audiences-tap-mobilenews-1c72525210d7

Lam, Shyong (Tony) K., Anuradha Uduwage, Zhenhua Dong, Shilad Sen, David R. Musicant, Loren Terveen, and John Riedl

2011 WP: Clubhouse?: An Exploration of Wikipedia's Gender Imbalance. In Proceedings of the 7th International Symposium on Wikis and Open Collaboration, pp. 1-10. ACM, Mountain View, California.

Lim, Sook

2009 How and Why Do College Students Use Wikipedia? Journal of the American Society for Information Science and Technology 60(11):21892202 
McAnany, Patricia A. and Sarah M. Rowe

2015 Re-Visiting the Field: Collaborative Archaeology as Paradigm Shift. Journal of Field Archaeology 40(5):499-507.

McDavid, Carol

2004 Towards a More Democratic Archaeology? The Internet and Public Archaeological Practice. In Public Archaeology, edited by Nick Merriman, pp. 173-202. Routledge.

McDavid, Carol, and Terry P. Brock

2015 The Differing Forms of Public Archaeology: Where We Have Been, Where We Are Now, and Thoughts for the Future. In Ethics and Archaeological Praxis, edited by Cristóbal Gnecco and Dorothy Lippert, pp. 159-183. Springer, New York.

McDowell, Zachary James (Principal Investigator)

2017 Student Learning Outcomes Using Wikipedia-Based Assignments: Fall 2016 Research Report prepared for the Wiki Ed Foundation. Electronic document, https://upload.wikimedia.org/wikipedia/commons/4/45/ Student_Learning_Outcomes_using_Wikipedia-based_Assignments_ Fall_2016_Research_Report.pdf

Perry, Sara, and Nicole Beale

2015 The Social Web and Archaeology's Restructuring: Impact, Exploitation, Disciplinary Change. Open Archaeology 1(1):153-165.

Richardson, Lorna-Jane

2012 Twitter \& Archaeology: An Archaeological Network in 140 Characters or Less. In Archaeology and Digital Communication: Towards Strategies of Public Engagement, edited by Chiara Bonacchi, pp. 15-24. Archetype Publications, London.

Rosenzweig, Roy

2006 Can History Be Open Source? Wikipedia and the Future of the Past. Journal of American History 93(1):117-146
Schroeder, Ralph

2018 Social Theory after the Internet: Media, Technology, and Globalization. UCL Press, London.

Thornton, Amara A.

2012 Wikipedia and Blogs: New Fields for Archaeological Research? In Archaeology and Digital Communication: Towards Strategies of Public Engagement, edited by Chiara Bonacchi, pp. 103-113. Archetype Publications, London.

Wright, Erik Olin

2011 A Call to Duty: ASA and the Wikipedia Initiative. ASA Footnotes 39(8):1, 6, 8.

\section{NOTES}

1. Under "Tools" in the menu bar on the left-hand side of each page, click "Page information," then scroll to "External tools" and click "Page view statistics."

2. Email address: contact@wikiedu.org

\section{AUTHOR INFORMATION}

Katherine M. Grillo Department of Anthropology, University of Florida, Gainesville, FL 32611, USA (kgrillo@ufl.edu, corresponding author) https://orcid. org/0000-0002-0131-6061

Daniel A. Contreras Department of Anthropology, University of Maryland, College Park MD 20742 https://orcid.org/0000-0002-8127-8789 